\title{
Pedagogical models from a lighting design studio
}

\author{
A. O. Asojo \\ Interior Design, College of Architecture, University of Oklahoma, USA
}

\begin{abstract}
This paper discusses a pedagogical approach for teaching a lighting design studio. Anderson's ACT-R theory is utilized to guide the learning process. Anderson's ACT-R theory focuses on three stages of skill acquisition: cognitive, associative, and autonomous stages. These three stages offer implications for teaching lighting. Early cognitivists offered many theories on how people solve problems. While early theorist focused mainly on explaining how people solve problems, contemporary theorist focus on cognitive strategies and information processes people use to solve problems. Knowledge is a key component of information processing in problem-solving. Cognitive Psychologist identified two distinct types of knowledge: declarative and procedural. Anderson notes "declarative knowledge is explicit knowledge which we can report and of which we are consciously aware". Procedural knowledge involves knowing how to execute tasks. Anderson notes "human cognition is always purposeful, directed to achieving goals and to removing obstacles to those goals". ACT-R's main assumption is that knowledge can be classified as declarative and procedural. Declarative knowledge is factual knowledge, while procedural knowledge is how to perform cognitive tasks. Students are taught accurate and elaborate knowledge of lighting design principles to help them problem-solving. Learning is achieved through expository and discovery methods. Expository are teacher centered examples of which include lectures and interactive presentations on lighting systems, as well as field trips to lighting laboratories and showrooms to offer real life context for students. The discovery method is emphasized in hands on experiences. Feedback is given during all three distinct phases of problem solving to correct any disequilibrium students may have. Eventually, students achieve automaticity due to continued practice.
\end{abstract}

Keywords: architectural lighting, cognitive strategies, lighting design, design problem solving and instructional design. 


\section{Introduction}

This paper discusses a pedagogical approach for teaching an architectural lighting design studio to third year Interior design students at the University of Oklahoma. Anderson's ACT-R theory [1] is utilized to guide students through the process of learning about architectural lighting design. Anderson's ACT-R theory [1] focuses on three stages of skill acquisition: cognitive, associative, and autonomous stages. These three stages offer implications for teaching a lighting studio and are analogous to stages employed in lighting design problem solving.

\section{Literature review}

\subsection{Cognition and problem solving}

Early cognitivists offered many theories on how people solve problems. For example, Wallas [5] identified the following four stages in problem solving: preparation, incubation, inspiration, and verification. Likewise, Polya [6] suggested four stages which rely heavily on cognition: understanding the problem, devising a plan, carrying out the plan, and looking backward. While early theorist focused mainly on explaining how people solve problems, contemporary theorist focus on cognitive strategies and information processes people use to solve problems.

Knowledge is a key component of information processing relevant to problem solving. Cognitive Psychologist identified two distinct types of knowledge: declarative and procedural. Anderson [2] notes "declarative knowledge is explicit knowledge which we can report and of which we are consciously aware" (p. 284). Procedural knowledge involves knowing how to execute tasks [2-4]. Anderson [2, p. 237] notes "human cognition is always purposeful, directed to achieving goals and to removing obstacles to those goals". Likewise, design problem solving involves solving problems and achieving client/user requirements.

\subsection{Anderson's ACT-R theory}

ACT-R (Adaptive Control of Thought-Rational) [1] was developed by John Robert Anderson at Carnegie Mellon University. The basic premise is that cognitive tasks humans perform consist of a series of separate actions and procedures. ACT-R's [1] main assumption is that knowledge can be classified as declarative and procedural. Declarative knowledge is factual knowledge i.e. knowledge of facts or how things are, while procedural knowledge is how to perform cognitive tasks. Anderson [2] notes "procedural knowledge is represented as productions or condition-action systems". For example, the hypothesis is, if certain conditions apply, then perform certain action [2].

According to Anderson, procedural knowledge is acquired in three stages of skill development: cognitive, associative, and autonomous. The first stage, the cognitive stage represents the phase in which "subjects develop a declarative 
encoding of the skill; that is; they commit to memory a set of facts relevant to the skill" [2]. The second stage, the associative stage results out of repeated practice. As a result of which performance becomes smoother and more rapid. This stage fosters practice which leads to proceduralization. As the procedure becomes more automated through practice, automaticity emerges in the autonomous stage.

\section{Process}

\subsection{ACT-R general implications for teaching architectural lighting}

Anderson's ACT-R general implications for teaching procedures are the following:

(i) Students must develop an accurate and elaborate declarative representation of the desired procedure (actions) and conditions under which it should be used;

(ii) Teaching can be accomplished using the expository or discovery methods. The expository method is teacher-centered instruction, while the discovery method occurs via discovery;

(iii) Feedback is an important component, because it fosters proceduralization; and,

(iv) Continued practice leads to automatization [2].

The accompanying chart Table 1 summarizes the application of ACT-R theory [1] to teaching sustainable strategies in lighting in the fall 2008, 2009, and 2010 lighting design studio. To apply these strategies in the lighting design studio in the first step, students are guided through the development of accurate and elaborative representation of lighting design principles. Examples of topics covered in lighting design studio to help students develop an accurate and elaborate representation in order to be able to design lighting systems include the following: lighting basics, design process, lighting concepts, lighting plans, reflected ceiling plans, electrical plans, luminaire types, perception and psychological aspects, lamp characteristics, light sources and color, distribution, efficient light sources, efficacy, material efficiency, photometry, lighting controls, energy management, codes, USGBC LEED rating systems, light pollution credit, energy performance credits, etc. This information is developed using the expository method which involves teacher-centered instruction, using interactive presentation lecture formats, as well as field trips to lighting laboratories and showrooms to offer real life context for students. Additional emphasis is placed on teaching students how lighting design plays a significant role in minimizing the impact on the environment.

For example, Winchip [7, p 284] notes "Sustainable design is a concept that focuses on products and processes that protect the environment and conserve energy for future generations. Whenever possible, lighting specifications should reflect the principles embodied in sustainable design. This involves selecting lighting systems that conserve energy and comply with standards, codes, and regulations". 
74 Lighting in Engineering, Architecture and the Environment

Table 1: Anderson ACT-R general implications for teaching lighting design.

\begin{tabular}{|c|c|}
\hline Task & Process \\
\hline $\begin{array}{l}\text { Develop accurate and } \\
\text { elaborate declarative } \\
\text { representation of } \\
\text { Lighting design } \\
\text { principles }\end{array}$ & $\begin{array}{l}\text { Lecture topics covered in Fall } 20082009 \text {, and } 2010 \text { courses: } \\
\text { - Week } 1 \text { - Introduction to lighting, lighting basics, design process, lighting } \\
\text { concepts, design elements and principles, and architectural elements; } \\
\text { - Week } 1 \text { - Lighting plans, Reflected Ceiling plans, Electrical plans. } \\
\text { - Week } 2 \text { - Lighting Workshop on 3D Studio Max presented by Adam Crespi, } \\
\text { professor of art and animation at DigiPen Institute of Technology, Redmond, } \\
\text { Washington. } \\
\text { - Week } 2 \text { - Vocabulary and Luminaire types; } \\
\text { - Week } 2 \text { - Perception and Psychological aspects; } \\
\text { - Okeek } 3 \text { - Field trip Smith Lighting, Oklahoma City, } 4101 \mathrm{~N} \text { Walnut Avenue } \\
\text { - Week } 3 \text { - Lamp Oklahoma; } \\
\text { output, Beam spread, Efficient light sources, Efficacy and Rated life, Material } \\
\text { Efficiency; } \\
\text { - Week } 3 \text { \& } 4 \text { - Photometry; } \\
\text { - Week } 5 \text { - Electricity and Electrical Controls; } \\
\text { - Week } 5 \text { - Outdoor lighting; } \\
\text { - Week } 6 \text { - Daylighting; } \\
\text { - College of Architecture Modelshop; } \\
\text { Week } 8 \text { - Energy management, Codes, Economics and Health; Energy and } \\
\text { environment; } \\
\text { - Week } 8 \text { - USGBC LEED Rating Systems - Light pollution reduction credit, } \\
\text { Energy performance credits, Controllability of lighting systems credit, Daylighting } \\
\text { and Views credit; } \\
\text { - Week } 9 \text { - Alternative energy systems: Photovoltaics and Wind turbines; } \\
\text { - Week } 9 \text { - Mechanical systems, Security systems and Fire suppression systems; } \\
\text { Week } 10 \text { - Presentation on lighting Historic Spaces and Guest Juror: Dawn } \\
\text { Hollingsworth, LC, IALD, Visual Terrain Inc., California, Managing Principal; } \\
\text { - Week } 11 \text { - Computer Modeling and Visualization in Form.Z, and; } \\
\text { Week } 12 \text { - Computer Modeling and Visualization in AGI } 32 \text { presented by Olivia } \\
\text { Flatt, Smith Lighting, Oklahoma City; } \\
\text { Note: Course materials, syllabus, lectures, project sheets, and PowerPoint files were posted } \\
\text { online at Course website at Learn.ou.edu }\end{array}$ \\
\hline $\begin{array}{l}\text { Expository Methods } \\
\text { (Teacher centered } \\
\text { instruction) }\end{array}$ & $\begin{array}{l}\text { Using the expository methods involved teacher centered instruction to help students } \\
\text { develop declarative knowledge. The above listed topics were presented in PowerPoint and } \\
\text { interactive presentation lecture format and field trips to lighting labs and lighting } \\
\text { showrooms in the vicinity to offer real life contexts for students. All these helped students } \\
\text { develop an understanding of fundamental principles in lighting. }\end{array}$ \\
\hline
\end{tabular}

In the second step, exercises where students learn by discovery are integrated. The discovery method is emphasized in hands-on experiences, some of which include a lighting analysis project, a store lighting design, a fixture design competition project, and a service learning community service project. In the lighting analysis project, student document and analyze three spaces in the vicinity: a store, an office space and a gallery space. In each space, student identify the different layers of lighting, types of luminaire, brightness hierarchy, concept, architectural opportunities and constraints, integration of lighting with 2D and 3D design elements, composition, quality, color, controls, sustainable 
Table 1: $\quad$ Continued.

\begin{tabular}{|c|c|}
\hline Discovery Methods & $\begin{array}{l}\text { The discovery method allowed students to learn through discovery. The following five } \\
\text { lighting design projects were accomplished during the semester. } \\
\text { Project 1: Lighting Analysis - Lighting analysis of a store, office space, and gallery. In } \\
\text { teams, student documented and analyzed three spaces in the vicinity: a Store, an Office } \\
\text { Space and a Gallery Space. In each space, student identified the different layers of lighting, } \\
\text { types of lum iniaire, brightness hierarchy, concept, architectural opportunities and } \\
\text { constraints, integration of lighting with 2D and 3D design elements, composition, quality, } \\
\text { color, controls, sustainable strategies implemented and user satisfaction. Students } \\
\text { documented these criteria using photographs, sketches, images, plans and notes in } \\
\text { PowerPoint (Appendix C - Illustrates a group's lighting Analysis project). } \\
\text { Project 2: Store Lighting Design - Lighting design of a contemporary brand name store. In } \\
\text { this project students designed the lighting and display space for a contemporary brand name } \\
\text { store in a metropolitan airport. Students' proposals were required to emphasize sustainable } \\
\text { issues, the different layers of lighting, brightness hierarchy, architectural opportunities, } \\
\text { composition, quality, color, controls, and integrate lighting solution with 2D and 3D design } \\
\text { elements in the space. } \\
\text { Project 3: Light Fixture Design - Light fixture design and full scale model of a light fixture. } \\
\text { Students were required to emphasize originality, creativity and energy efficiency in the } \\
\text { Luraline Light fixture competition. } \\
\text { Project 4: Norman Senior Citizen Center -Lighting design of the Norman Senior Citizen } \\
\text { Center housed in the old Norman public library building. Interior Design students designed } \\
\text { the interiors and lighting along with Graduate architecture students. The project involved } \\
\text { lighting a dining hall, gallery, and multipurpose hall } \\
\text { Project 5: Restaurant in Nigeria and South Africa - Lighting Design of a restaurant in an } \\
\text { urbane setting in Lagos, Nigeria or Johannesburg, South Africa to highlight the country's } \\
\text { culture and foods to tourist. }\end{array}$ \\
\hline Feedback Component & $\begin{array}{l}\text { Feedback was an important component, because it fosters proceduralization. } \\
\text { Three distinct Phases are identified for each design project and feedback from the instructor } \\
\text { and jurors occurred in these three distinct phases in all four projects. } \\
\text { Initial Phase - Information Gathering and Programming } \\
\text { This phase involved an analysis of owner and design team preferences, architectural } \\
\text { opportunities and constraints, visual and perceptual needs, photometric considerations, } \\
\text { security issues, budget, energy code requirements, sustainable strategies, and maintenance } \\
\text { considerations. The requirement at this phase was a concise program. } \\
\text { Design Concept Phase } \\
\text { In this phase, students were expected to develop their concepts to provide appropriate } \\
\text { quality and quantity of light for visual tasks performed, respond to psychological needs of } \\
\text { the users, and enhance architectural design features. Some common composition techniques } \\
\text { to be explored at this stage include mood/atmosphere, sparkle/smoothness, uniform/non- } \\
\text { uniform, brightness hierarchy, and way finding. } \\
\text { Design Development Phase } \\
\text { In this phase, students develop their final design options as presentation drawings and } \\
\text { schedules. Presentation drawings included lighting layout, details, renderings, and } \\
\text { specifications. }\end{array}$ \\
\hline $\mathrm{Al}$ & $\begin{array}{l}\text { Continued practice led to automatization and this was evident by the increase in the quality } \\
\text { of the work developed by the students as the semester proceeded. }\end{array}$ \\
\hline
\end{tabular}

strategies implemented and user satisfaction. Students document these criteria using photographs, sketches, images, and plans. In the store lighting design project, students design the lighting and display space for a contemporary brand name store in a metropolitan airport. Students' proposals are required to emphasize sustainable issues through using the different layers of lighting, brightness hierarchy, architectural opportunities, composition, quality, color, controls, and the integration of lighting solution with 2D and 3D design elements in the space (Figures 1 and 2). In the light fixture design, students are required to emphasize originality, creativity and energy efficiency in the design of a full scale model of a light fixture (Figure 3). In a final project, usually a service learning or a community service real life project, students emphasis sustainable issues in their solutions. 


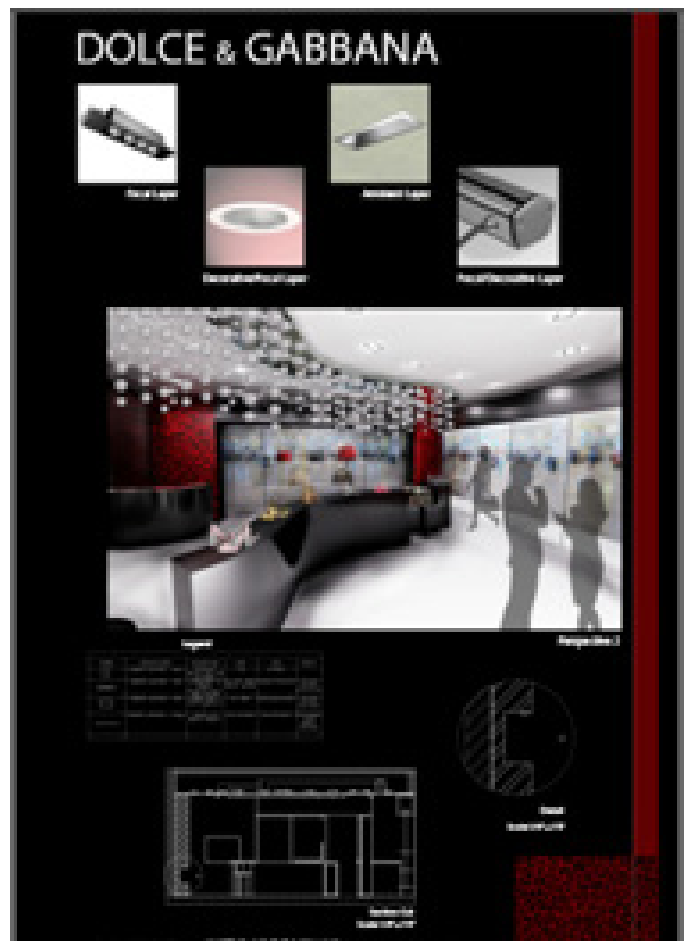

Figure 1: $\quad$ Store lighting design project by Katya Yarominak, cooper lighting source award of recognition April 2010.

The three distinct phases utilized in lighting design problem solving are information gathering and programming, design concept and design development. The information gathering and programming phase involves an analysis of owner and design team preferences, architectural opportunities and constraints, visual and perceptual needs, photometric considerations, security issues, budget, energy code requirements, sustainable strategies, and maintenance considerations. The requirement at this phase is a concise program.

In the design concept phase, students develop their concepts to provide an appropriate quality of light for visual tasks performed, respond to psychological needs of the users, and enhance architectural design features. In the design development phase, students develop their final design options as presentation drawings and schedules which include lighting layout, details, renderings, and specifications. Feedback is given during all three distinct phases of problem solving in all four projects. This feedback helps to correct any disequilibrium students may have. Disequilibrium is a state of misconception or misinformation. Finally, students achieve automaticity through continued practice as they complete the lighting design projects and advance to upper levels courses. 

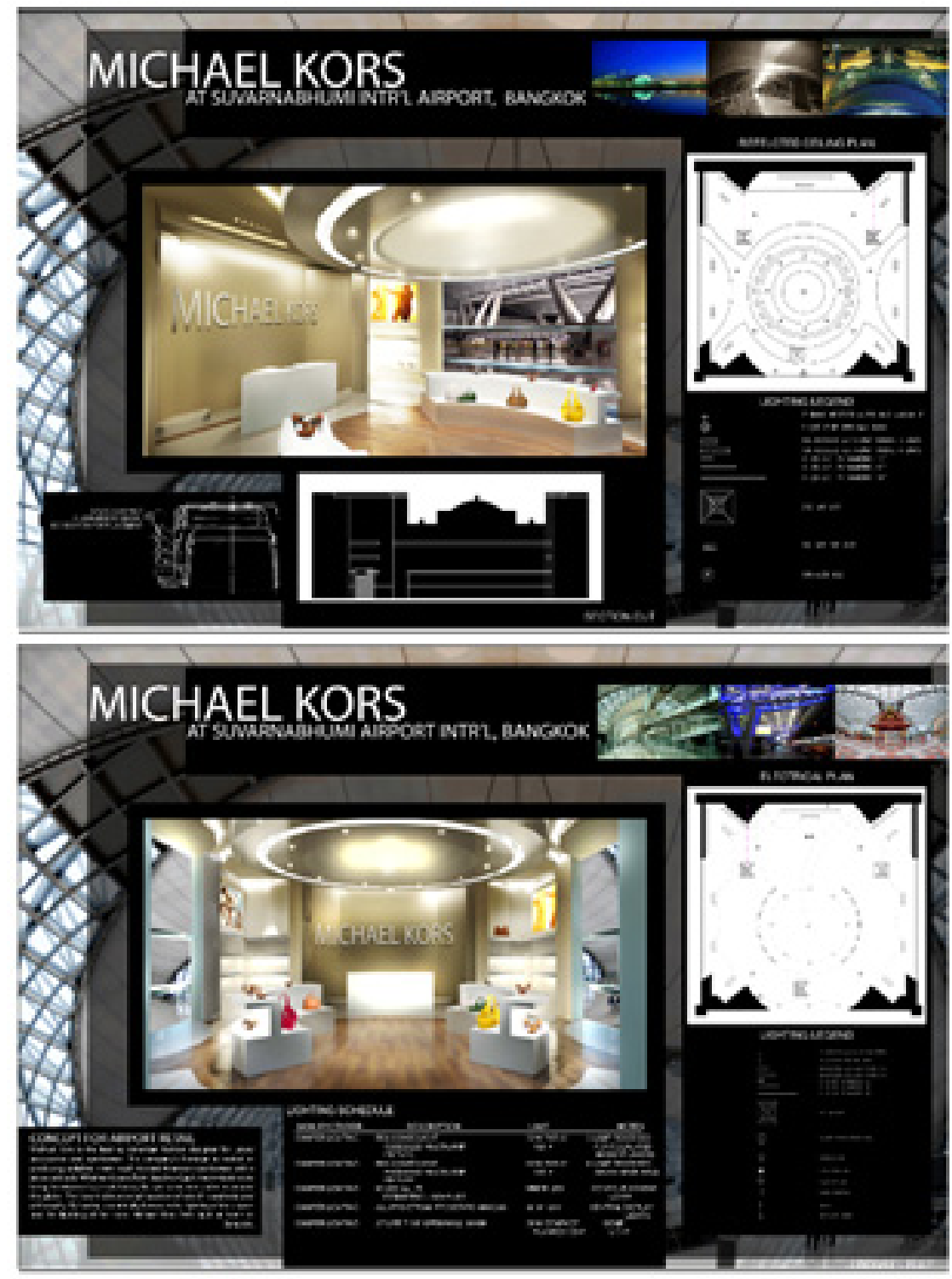

Figure 2: $\quad$ Store lighting design project by Lindsay rule. 


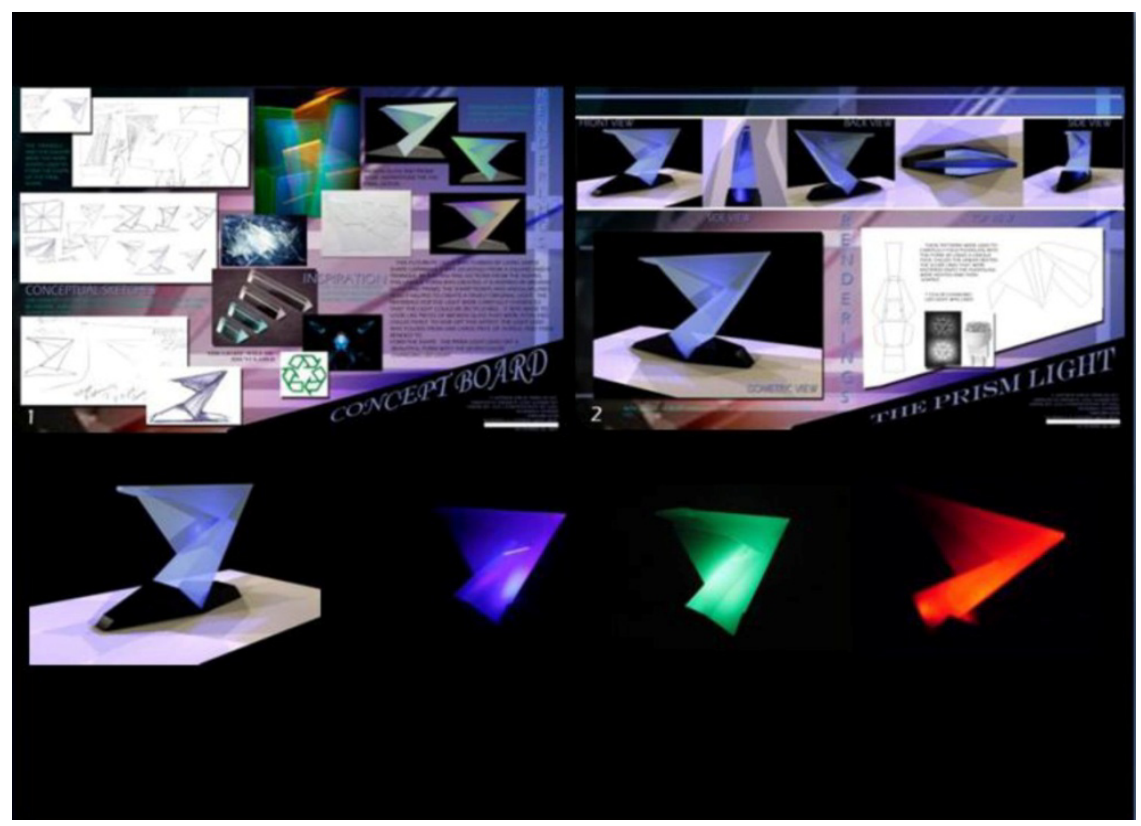

Figure 3: $\quad$ Fixture design, $1^{\text {st }}$ place winning entry in 2008 Luraline fixture design competition by Marissa Gomez.

\section{Conclusion}

This paper illustrates how students acquire design skills in an architectural lighting design studio through the utilization of Anderson's ACT-R theory [1] in the instructional process. Using Anderson's ACT-R theory [1] in the instructional process for this lighting design studio has been very effective because since 2008, projects from the lighting design studio have won national design competition and have been widely disseminated. For example, student work from the fall 2008 lighting studio was published in an article titled "Branding with Light-Interior Design Students at University of Oklahoma propose distinctive illuminated Store plans" in April 2009. In May 2008, Marissa Gomez won $1^{\text {st }}$ place nationally in the Luraline fixture design competition. The jurors commended her innovative use of sustainable materials and energy efficient lamp sources in her design solution. In April 2010, Katya Yarominak won a Cooper lighting Source Award of recognition for her store lighting design project.

While architectural lighting is a vast topic, ACT-R theory [1] can effectively help design students gain a better understanding of lighting systems and help them become better designers. Future direction of this research will aim at including more student meta-cognitive strategies such as self-regulation or selfmonitoring in the process since Anderson's ACT-R [1] procedure is very systematic and procedural. 


\section{References}

[1] Anderson, J.R., The Adaptive Character of Thought. Hillsdale, New Jersey: Erlbaum,1990.

[2] Anderson, J.R. Cognitive Psychology and its Implication. New York: Freeman, 1995.

[3] Anderson, J.R., The Architecture of Cognition. Cambridge Massachusetts: Harvard University Press, 1983.

[4] Corno, L., Cronbach, L. J., Kupermintz, H., Lohman, D.F., Mandinach, E.B., Porteu, A.W., \& Talbert, J.E., Remaking the concept of aptitude: Extending the Legacy of Richard E. Snow. Mahwah, New Jersey: Erlbaum, 2002.

[5] Wallas, G., The Art of Thought. New York: Harcourt, Brace and Company, 1926.

[6] Polya, G., How to Solve it: A New Aspect of Mathematical Method. New Jersey: Princeton, 1971.

[7] Winchip, S.M., Designing a Quality lighting Environment. New York: Fairchild., 2005. 